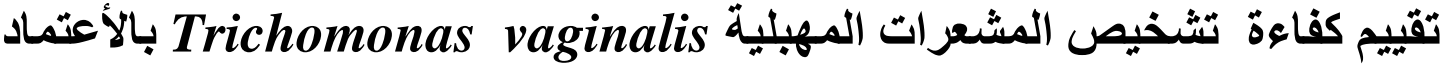

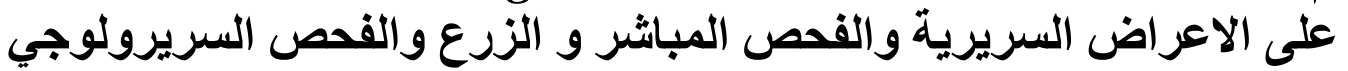

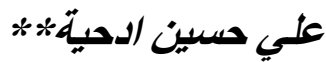

\author{
أمنة نصيف جاسمث*

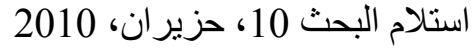

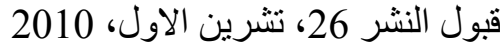

| (خلاص مشرف

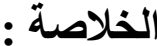

بحثت الدر اسة بيان مدى كفاءة الأختبار ات التشخيصبة وتحديد طبيعة الأعر اض السريرية في الكثف عن التبن

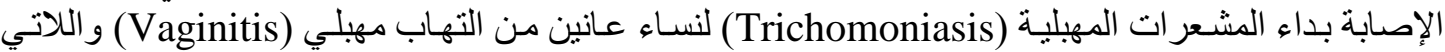

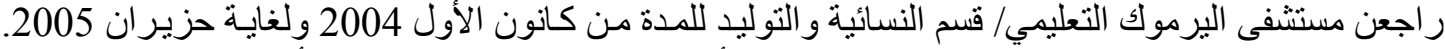

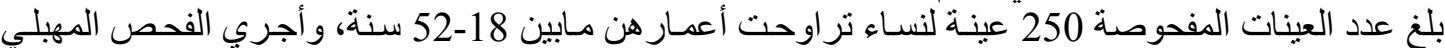

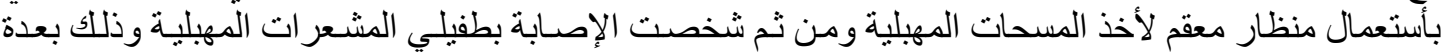

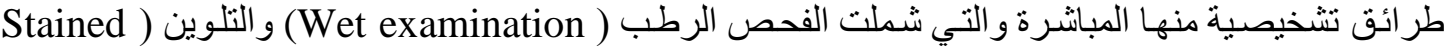
Kupferberg Trichomonas Broth) بملون لثمان، و الأستنبات في أوساط زر عية متباينة (examination B و Base

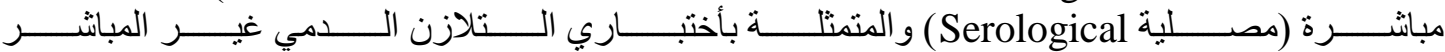
Enzyme Linked و الممتز المناعي المرتبط بالأنظيم (Indirect Haemagglutination Test; IHAT) Immunosorbent Assay; ELISA

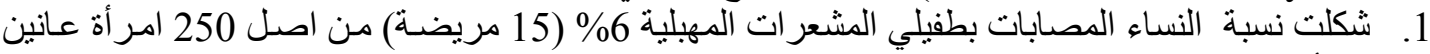
من أفرازات مهبلية غير طبيعية.

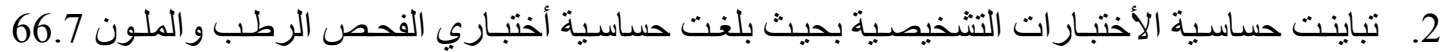

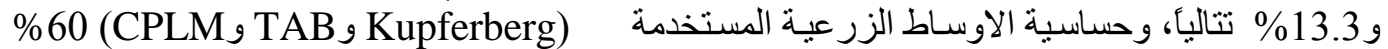

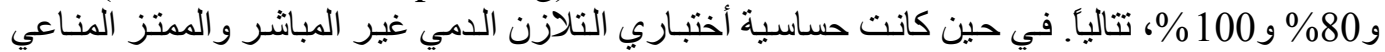

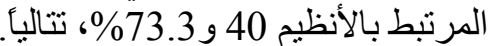

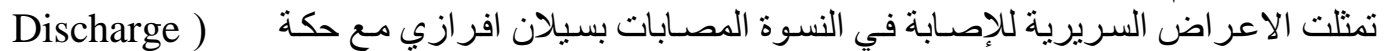

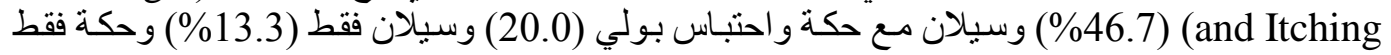

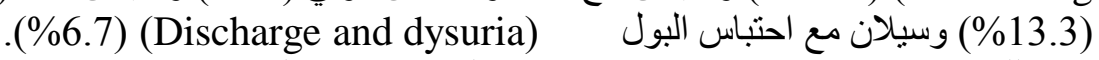

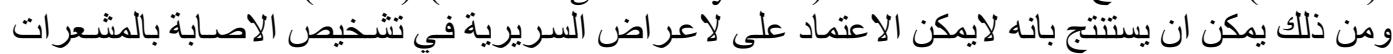

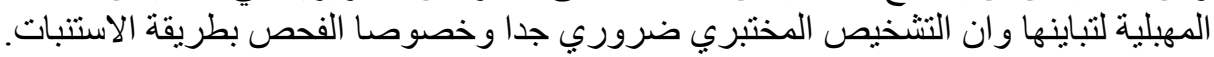

الكلمات المفتاحية:Trichomoniasis; serological test; cultivation; clinical sign

العلامات السريرية بتباين شدة الإصـابة، وهذا مـا

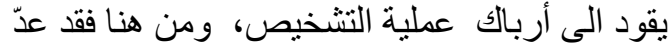

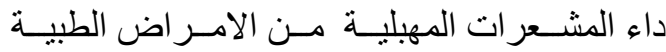

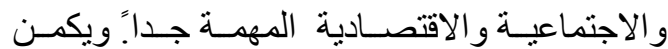

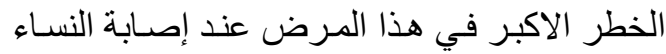

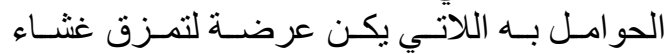

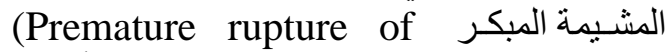
placental membrane) حديثي الولادة (Low birth weight infants).

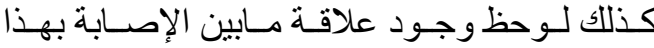

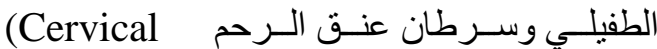
( cancer) دعت الحاجة الى أيجاد طريقة مثلى في تشخيص

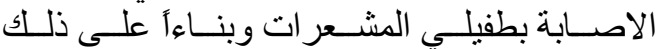
صمدت الدر اسة الحالية بهذف تسليط الضوء على الئى
المقدمة : بعد طفيلي المشعر ات المهبلية (Trichomonas vaginalis)

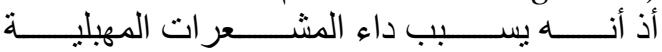

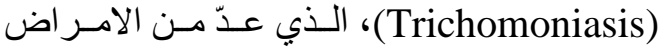

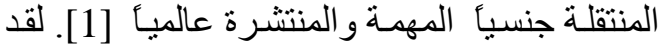

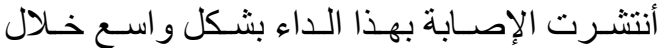

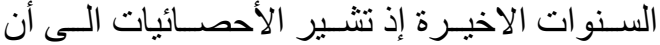

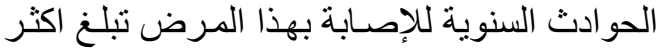

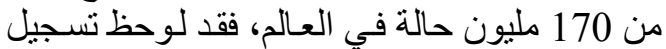

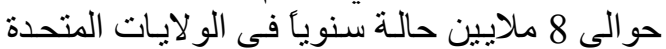

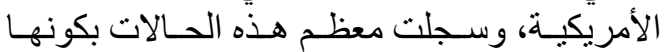

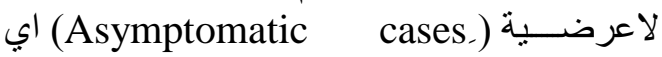
لاتظهر لها علامات سريرية [2]، لذا لايمكن تمييز

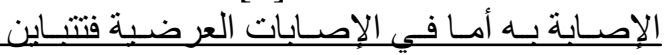

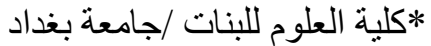
***وحدة الابحاث البايولوجية للمناطق الحارة/كلبة العلوم جامعة بغداد 
لفصل المصل. قسم المصل في أنابيب أنبدورف

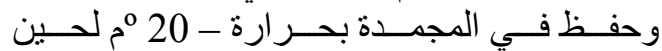

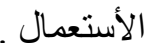

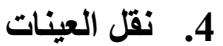

نقلت العينات ( المسحات المهبلية و عينات الدم ) الى المركز الوطني لأمر اض السكري التابع التابع

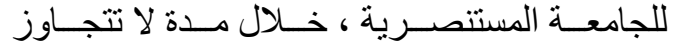
الساعنين من وقت آخذ العينة . العية 5.تثخيص الأصابة بالمشعرات المهبلية

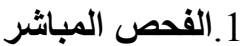

فحصت عينة أحدى المسحات المهبلية وذلك الكئ Smear) من خلال عمل شريحتين ، الأولى مسحة المرة

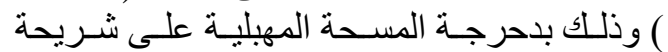
زجاجية نظيفة و تركت لتجف بدرجة حر ارة الغرفة

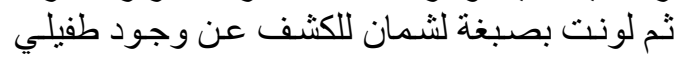
المشعر ات المهبلية بالتلوين ـ بعد ذلك اضلك اضيف 0.5

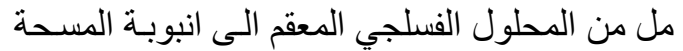

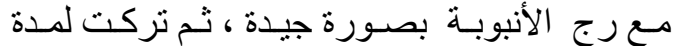
دقيقتين و آخذت بعد ذلانك قطرة من نقيع المسحة

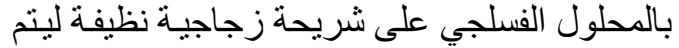

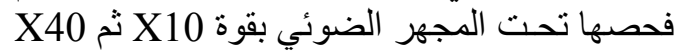

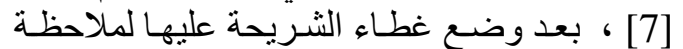

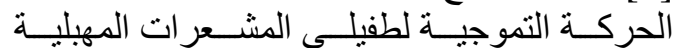

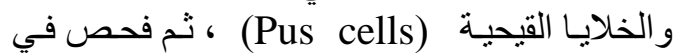
الاقل 20 حقلا مجهرياً ، وقد عد الفحص موجبأ في في الفي

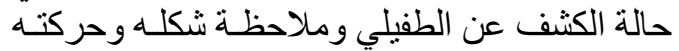

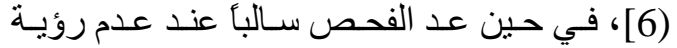
الطفيلـي خـلال مـــة تتـر اوح مـن 3-5 دقــائق مـن

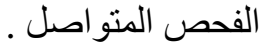

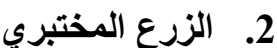

زرعت المسحات المهلبية الثناث الباقية لكل

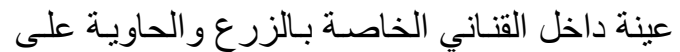

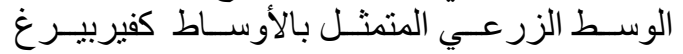
Kupferberg Trichomonas Broth Base Trichomonas modified (CPLM ) المحسورو) Trichomonas Agar (TAB Base و المجهزة مـن قبـل شـركة Himedia كلا على حدة، ثم حضنت هذه الأنابيب بعد تعليمها برقة

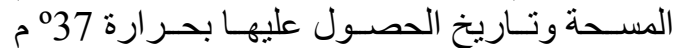
هو ائياً. فحصت ونـاريخ هذه العينـات يومياً و على مدار 7 ايام لاعطاء النتيجة النهائية . إدامة طقيلي المشعرات المهيلية:

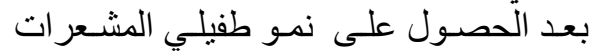

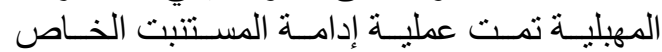

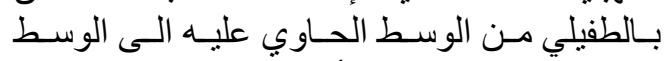

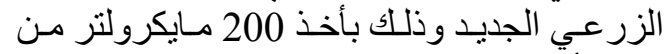

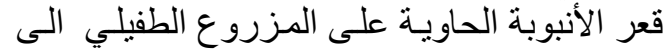

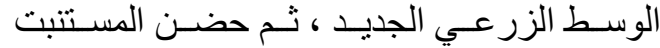

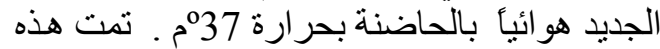

الجو انب الأتية للإصـابة بطفيلي المشعرات المهبلية

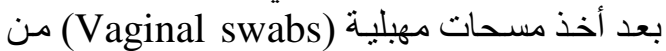
نساء عانين من أفراز ات مهبلية غبير طبيعية

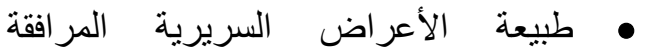

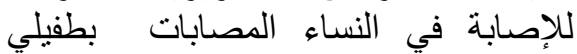
المشعرات المهبلية.

توظيب طرائق عديدة في تتخيص الرئ

الإصابة، الني شملت الفحص الرطب ( Stained ( ) والفحص الملون (preparation (examination أوساط زرعية، فضلا عن الفحوصات المصلية والمتمثلة بأختبار التلازن (Serological tests)

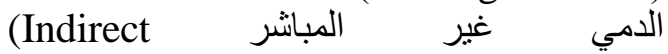
(اختبار الممتز (Enzyme linked المناعي المرتبط بالأنظيم بهدف الكثف عن مدى Immunosorbent test) حساسية هذه الأختبار ات في التشخيص

$$
\text { المواد وطر ائق العمل: }
$$

Patients المريضات

1. جمع المعلومات الخاصة بالمريضات المات

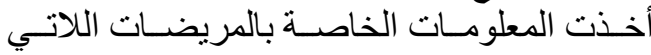

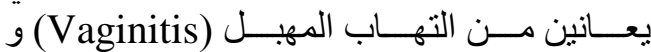

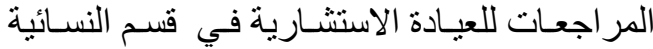

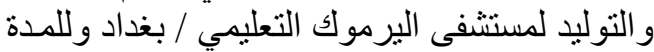

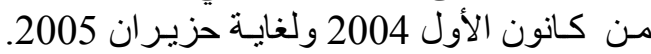

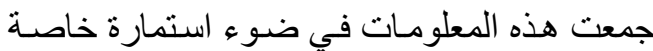

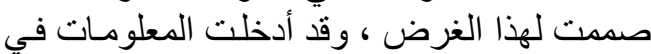

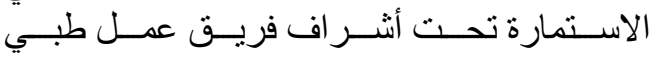

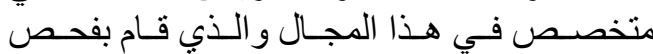

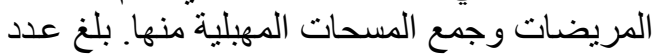
المريضات 250 امر أة.

\section{2. of Vaginal Swabs}

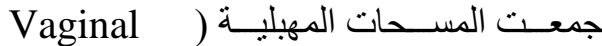

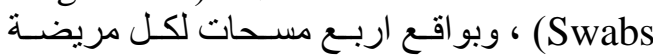

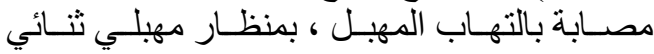
الفتحسات معقم (Sterile Speculum ) بعـانـ

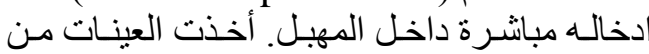
عنق الرحم ( Posterior Fornex) و الجدران

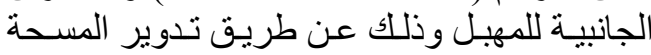

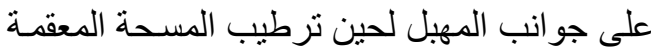
و والمعدة لهذا الغرض مع أخذ الخدة (Sterile Swab)

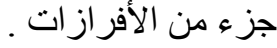

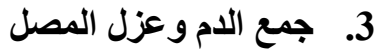

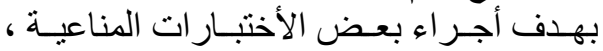

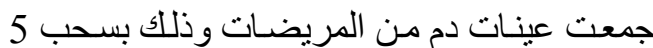
مل من الدم بمحقنة نابذة ـ ثم وضع الدئح الدم في انابيب بلاستيكية وترك ليتجلط بلدرجة حرة درارة الغرفة لئة ليتم نبذه بسر عة 3000 دورة / دقيقة ولمدة 10 دقائق لئق 
ضد طفيلي المشعر ات المهبلية في مصول النسوة

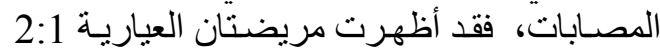

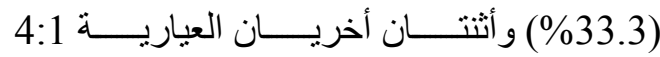

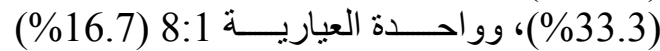
والأخيرة العيارية 16:1 (16.7\%) شكل (1). أما أسا

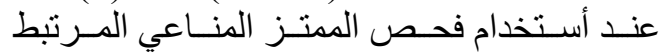

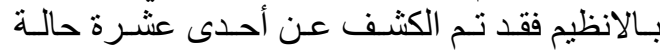

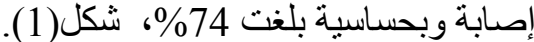

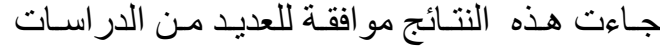
السابقة التي كثفت عن التباين الحاصل في كفاءة التهاء

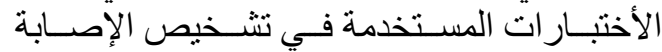
بطفيلي المشـعرات المهبليـة، فقد أثشير الـى تبـاين الإني

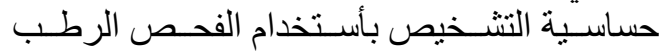

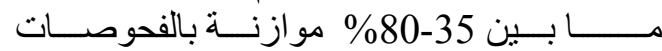

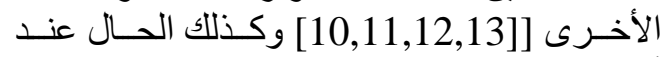

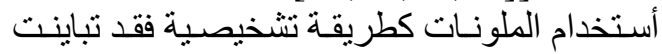

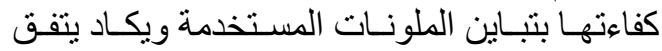

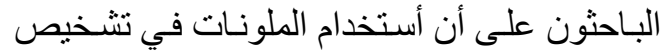

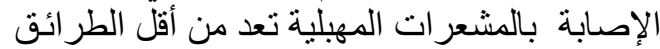

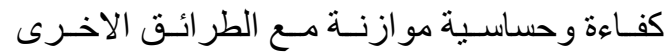

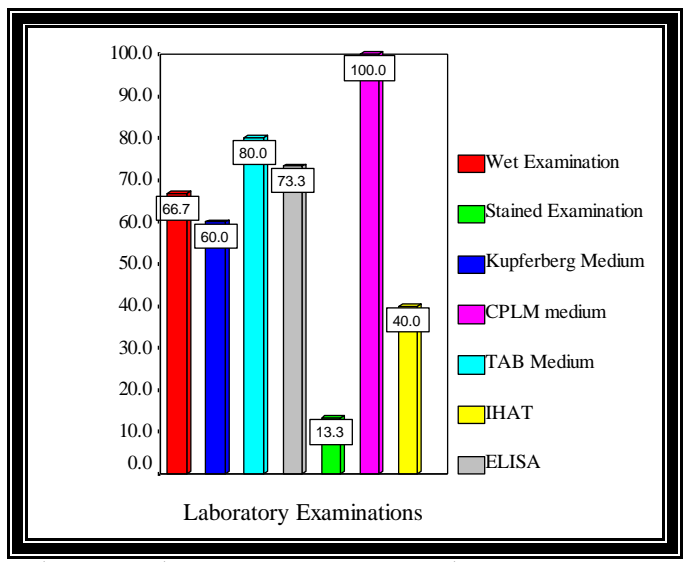

شكل 1: حساسية الفحوصات المختبرية المختلفة لتشخيص الإصابة بطفيلي المشعرات المهبلية.

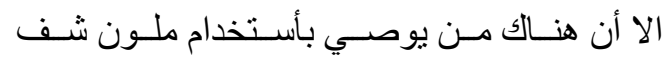
حامض البريـودك (Periodic acid schiff)

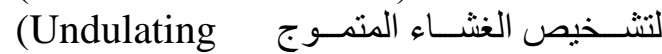
membrane)

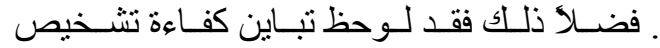

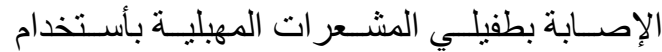

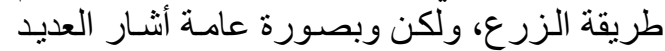
من الباحثين الى أن هذه الطريقة فاقت في في قدرتها

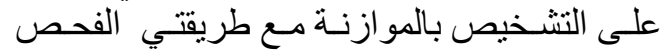

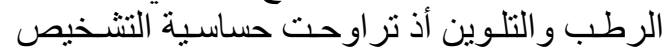

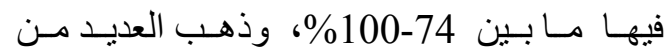

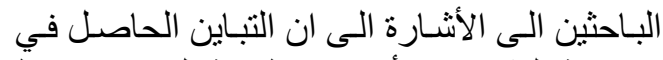

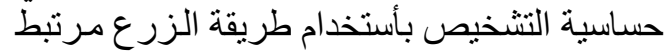

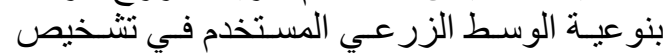

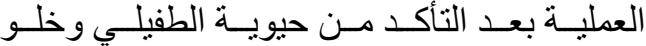

$$
\begin{aligned}
& \text { المستنتبت من التلوث. } \\
& \text { 3.الأختبارات المصلية } \\
& \text { أختبار التلازن الدمي الغير مباشر }
\end{aligned}
$$

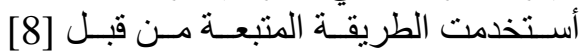

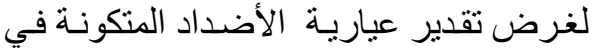

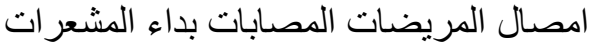

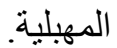

1.اختبار الممتز المنـاعي المرتبط بـالأنظيم اجري

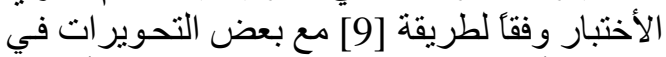

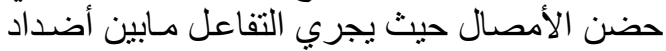

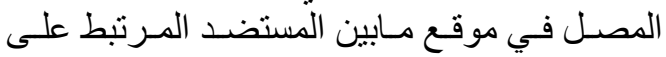

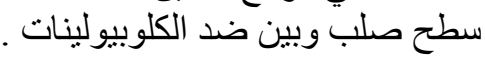

\section{النتائج والمناقشة:}

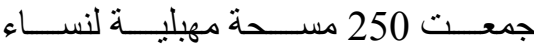

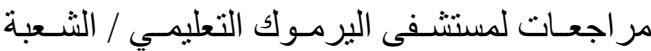

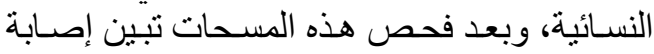

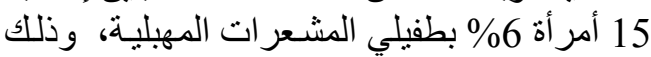

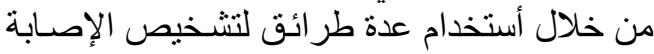

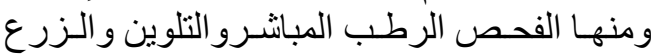

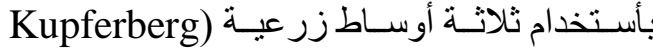

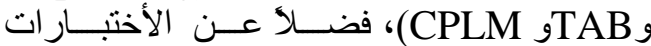

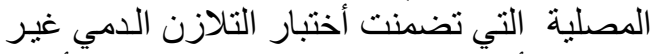

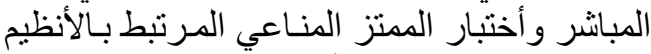

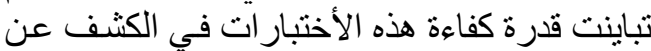

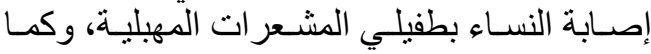

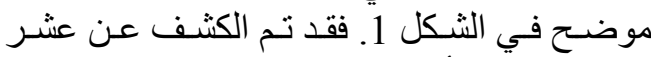
حالات إصأبة بأستخدام الفحص الرطب الفي وبحساسية

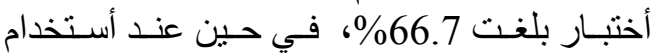
طريقة التلوين بملون لثمان (Leishman stain)

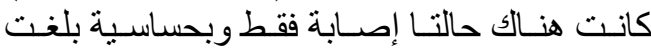

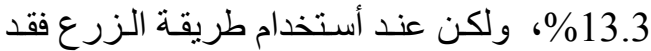

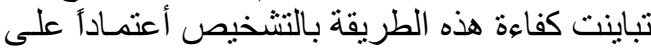

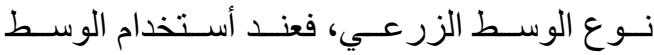

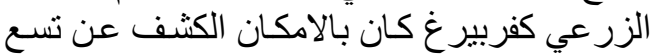

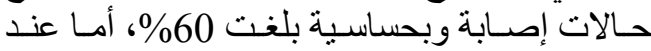

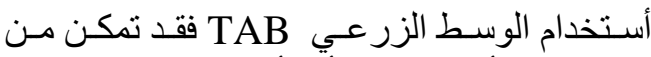

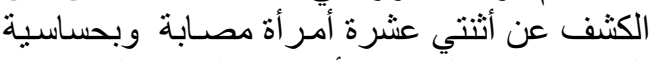

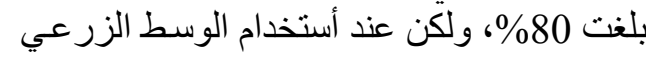

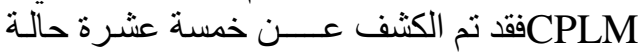

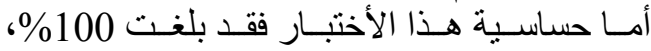
ولكون هذا الوسط كثف عن أكبر عدد من النساء

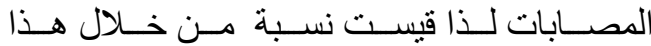

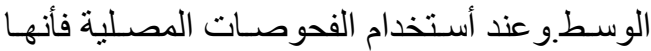

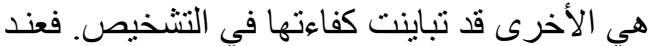

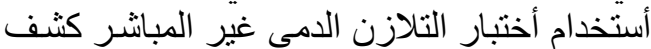

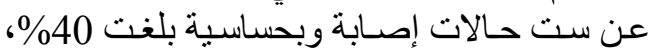
وقد تباينت هنا عياريـة (Titer) الأضداد المتكونـة 
لنساء عانين من سيلان أفر ازي مـع حكة و أحتبـاس

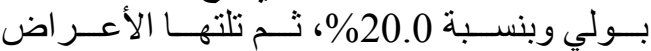

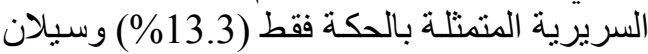

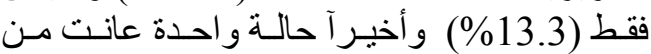
سيلان مسع أحتبـاس بـولي (6.7\%) (الجدول 1) 1). فضلا عن ذللك فقد تباينت طبيعة السيلان الأفرازي بدوره وبحسب الصفة اللونيـة التي يحملهـا وكمبـا موضح في الجدول2 ، من حيث أفرازات عديمة اللـات اللـون (Colorless discharge) أو أفـرازات ذات طبيعـة رغويـة (Frothy discharge) أو آو آ سيلان أبيض (White to gray dischar) وأخير آسيلان أصفر مخضـر ( Yellow to

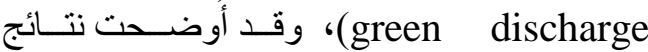
الدر اسـة الحاليـة أن أعلى نســـة إصـابة بطفيلـي

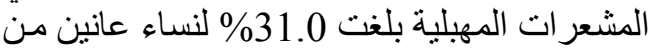

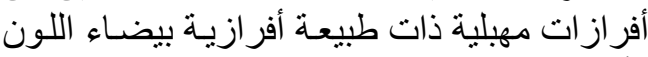

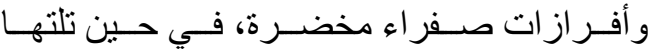

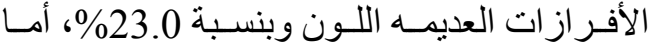

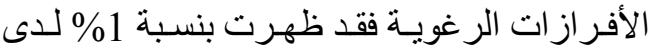

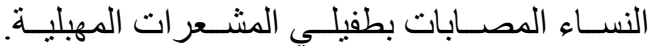

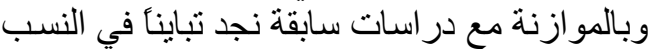

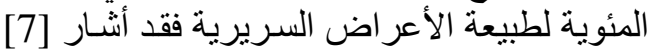

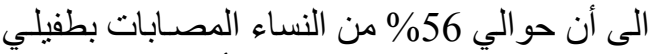

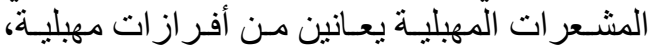
وأن حو الي 12\% من طبيعة هذه الأفراز ات كات كانت

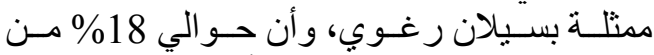

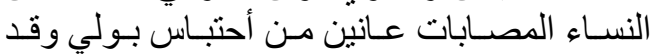

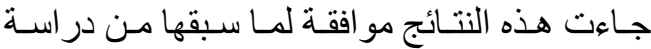

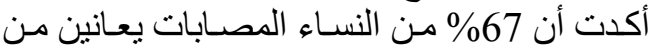

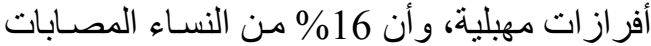

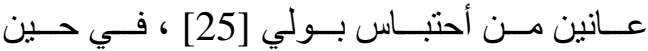
أكد (1989) أن أن أن

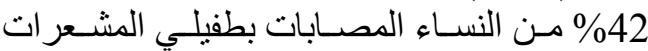

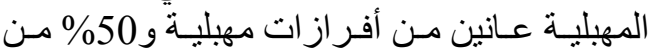

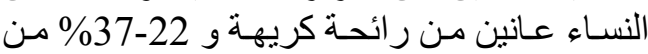

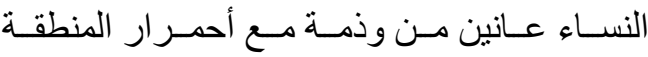
(Edema and redness) المصابات اللاتي عانين من أفراز ات مهبلية كانت الأفراز ات ذات طبيعة رغوينة

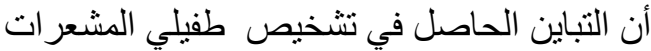

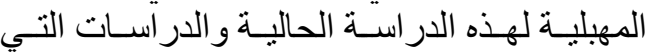
سبقتها ممكن ان يفسر في ضون الفو ما يلي:

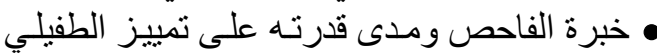

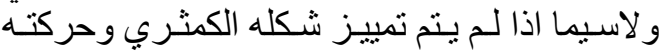

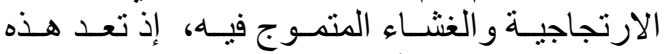

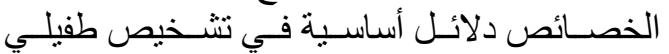

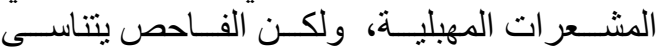

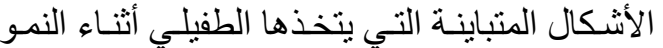

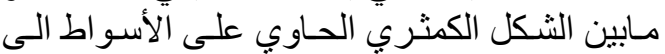

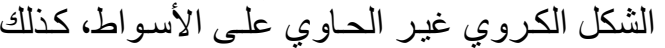

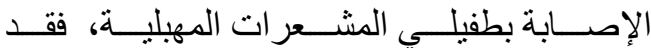
أشار [16]الى ان الوسط الزي الزعي دايموند الدحور هو أكثر حساسية في

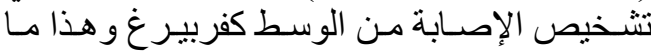

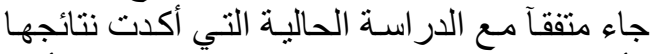

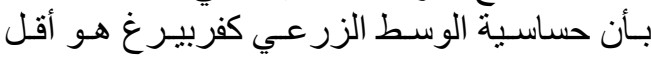

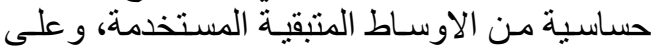

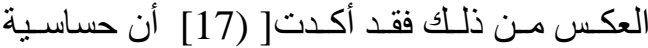

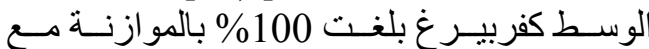

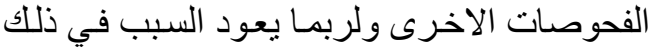

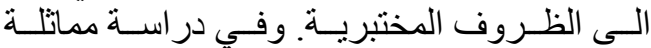

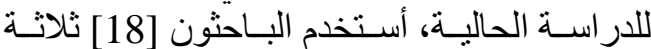

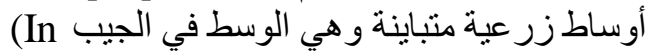

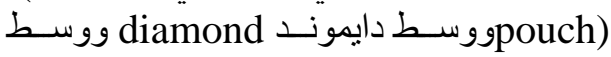

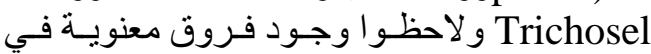

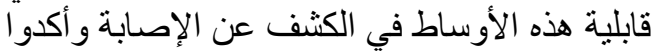
أن الوسط في الجيب هو أكثر حساسية من الوسط الإسط

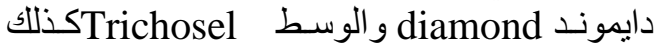

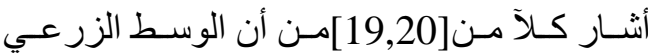

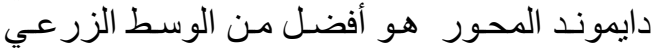
دايموند الاصلي.

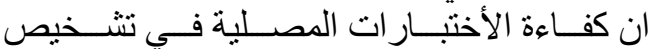

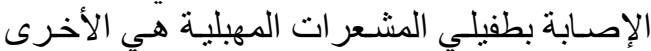

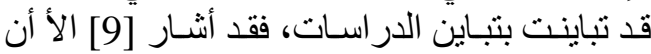
حساسية أختبار الممتز المناعي والمرتبط بـالأنظيم

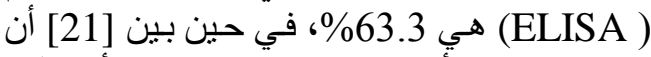

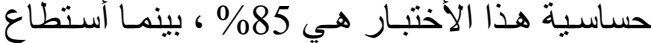

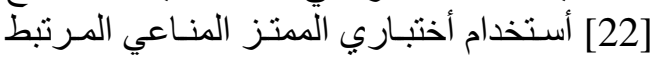

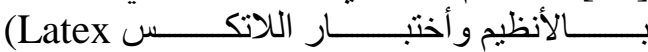
agglutination)

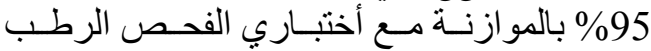

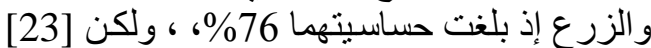

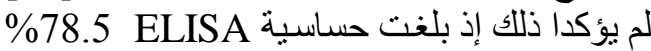

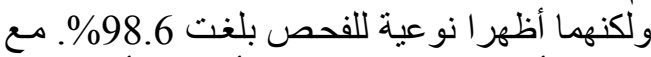

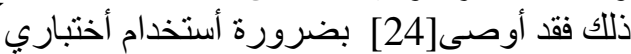
PCR وELISA

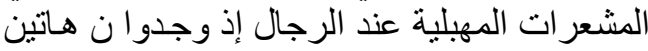

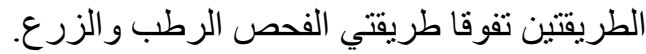

\footnotetext{
الأعراض السريرية المصاحبة للإصابة بطقيلي المشعرات المهبلية : الاعية المبرية

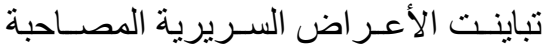

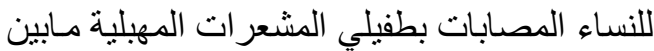

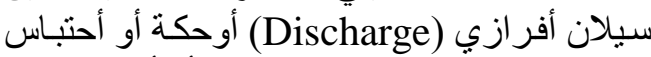
البول (Itching or dysuria) أو أن الإصـابة ألمانة

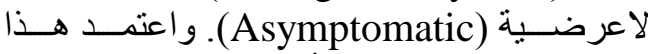

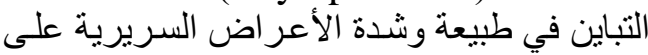

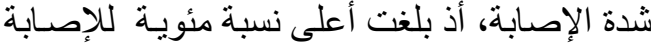

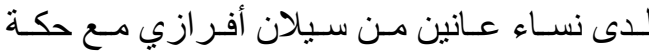

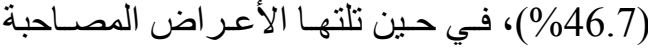




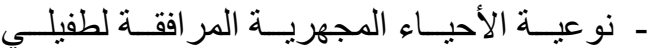
المشعرات المهيلية، فقد أثـار العديد من البـاحثين

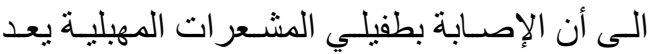

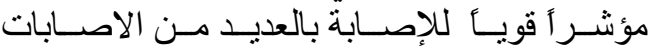

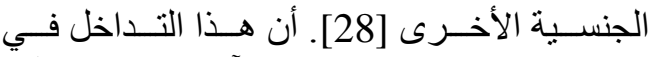

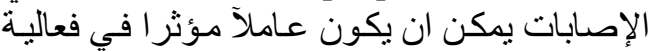

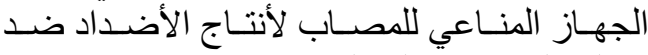
طفيلي المشعر ات المهبلية.

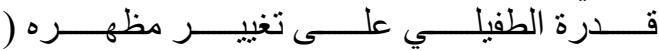
(Phenotyping variation

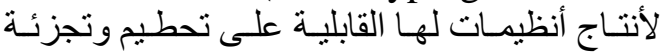
الأضداد المتكونـة ضـده، كذللك قابليته على ألى أنتاج

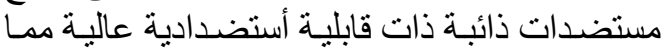

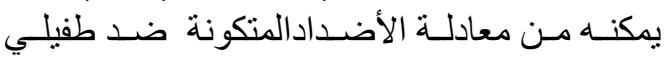
الششعر ات المهبلية[29,30,31

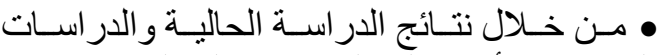

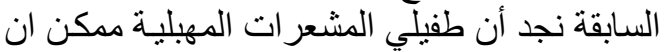

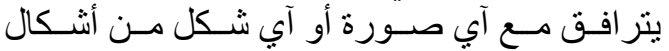
الأعر اض السريرية وهذا ماجاء متفقآ لما آنشار اليه آنسا Fouts and karus (1980)

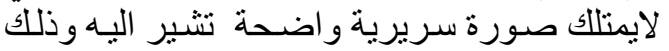

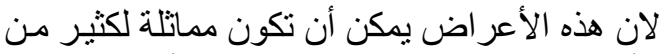

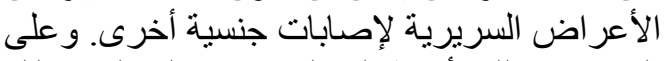

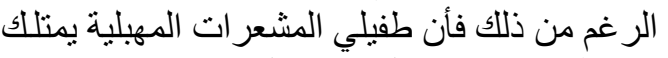

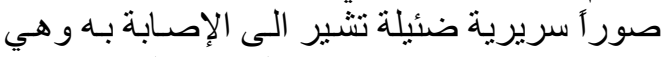

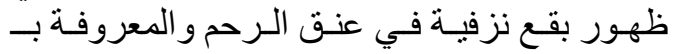
Strawberry

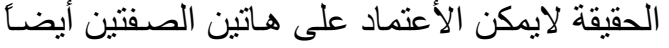
وذللك لسببين هما :

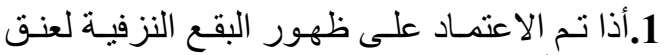
الرحم فأن هذه الصفة السريرية لاتظهر الابنسبة الصنة

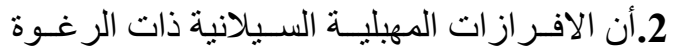

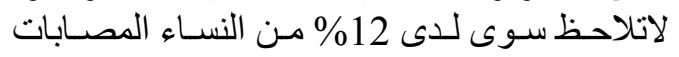
بطفيلي المشعر ات المهيلية.

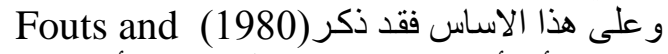
Kraus

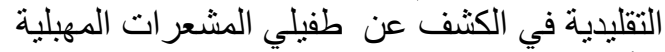

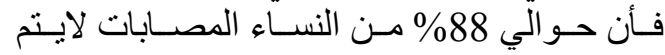

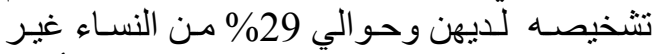
المصابات سيشار اليهن وبشكل خـاطئ على ألى أنهن

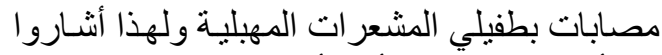
الى أن هذه العلاّمات أو الأعر اض الت السريرية ليست عو امل تنخيصية موثوقة.
التباين الحاصل في حجم الطفيلي الذي يعتمد بشكل

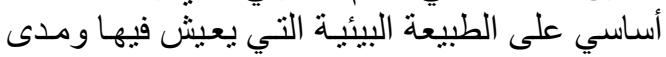

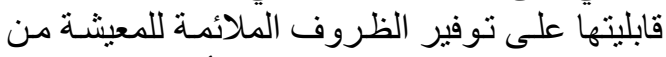

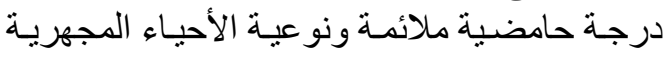

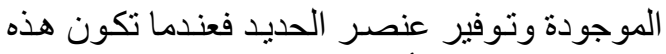

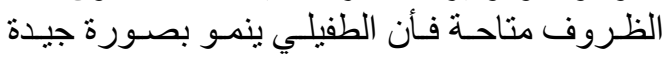
ويعطي الشكل المتعارف علية وهو الثنكل الكمثري

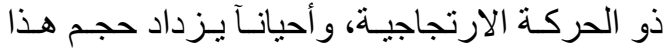

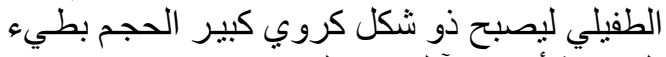

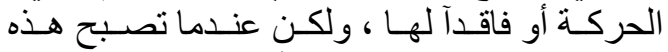

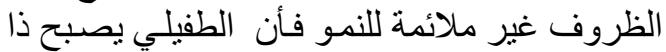
شكل دائري عديم الحركة وفاقدأ للاسو أط , و وهذا

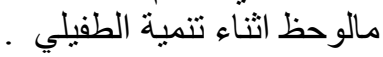

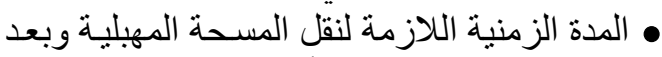

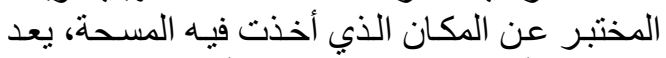

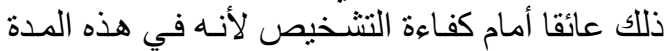

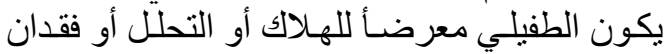

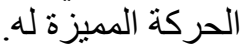

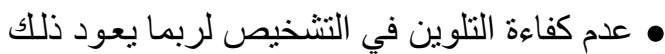

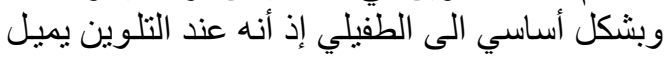

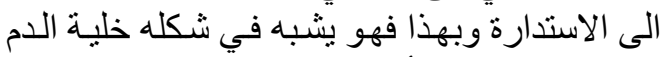

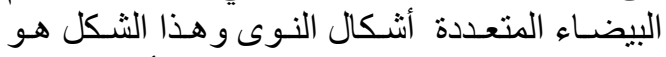

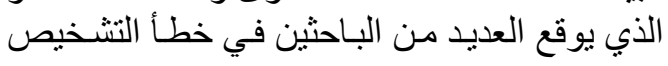

• الوقت الذي يتم فيه أخذ المسحة المهبلية وهل هو

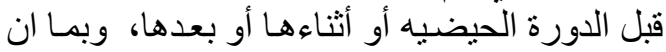

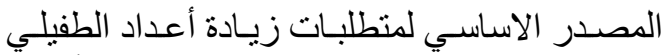

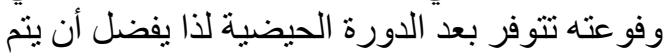
أخذ العينه بعد أنتهاء الدورة مباشرة.

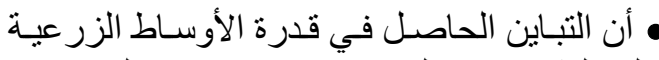

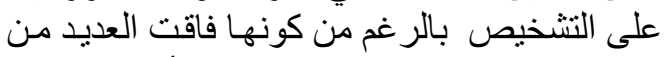

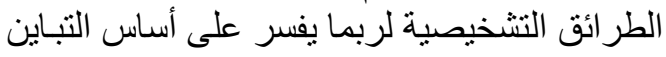

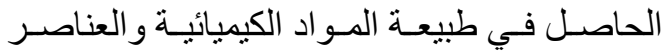

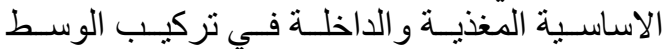

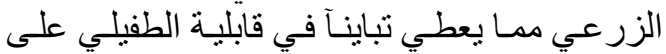
النمو و التكاثر

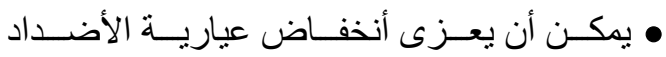

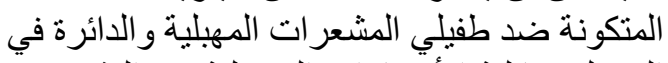

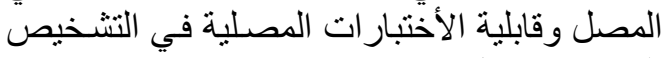
الى عدة عو امل منها: - معت وقت الإصـابة (Duration of infection)، فالمعروف أن الإصـابة بطفيلي المشعر ات المهبلية

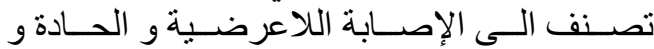
المزمنة، و أمكانية حصول تثبيط منساعي و لاسبيا

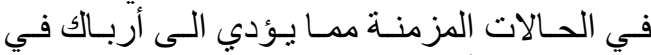

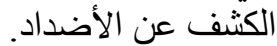


$\begin{array}{lrr}\text { between } & \text { sexually } & \text { transmitted } \\ \text { pathogens } & \text { and } & \text { cervical }\end{array}$ intraepithelial neoplsia in a developing community. Genitourin. Med., 69:357-360.

6. Thomason, J.L. and Gelbart, S.M. 1989.Trichomonas vaginalis. Obstet. Gynecol., 74:536-541.

7. Fouts, A.C. and Kraus, S.J. 1980. Trichomonas vaginalis: reevaluation of its Clinical presentation and laboratory diagnosis .J.Infect. Dis .41:137-143.

8. Farshy, D. C. and Gagan, I. G. .1971. Use of stable sensitized red cells in indirect microhaemagglutination test for malaria. Am. J. Trop. Med. Hyg., 21: $868-872$

9. Street, D.A., Toylor-Robinson, D., Ackers, J.P., Hanna, N.F and McMillian, A. .1982. Evaluation of an enzyme -1 inked Immunosorbent assay for the detection of antibody to Trichomonas vaginalis in sera and vaginal secretion. Br. J. Vener .Dis., 58:330-333 .

10. Draper, D., Parker R. , Patterson, E. , Jones, W. , Beutz, M. , French, J., Borchardt, K. , and McGregor, J. 1993. Detection of Trichomonas vaginalis in pregnant women with the In pouch TV culture system. J. Clin. Micobiol ., 31:1016-1018

11. Lawing, L. F., Hedges, S. R. and Schwebke, J. R. 2000. Detection of trichomoniasis in vaginal and urine specimens from women by culture and PCR. J. Clin. Micobiol., 38:3585-308

12. Madico, G. ， Quinn ， T.C., Rampalo, A. ; Jr, K.,T., M. and Gaydos, C.,A., 1998. Diagnosis of Trichomonas vaginalis infection by PCR using vaginal swab samples. J. Clin . Micobiol., 36:3202-3210.

13. Heine , P. and McGregor, J. A. 1993. Trichomonas vaginalis
جدول(1): الأعراض السريرية المصاحبة لإصابة

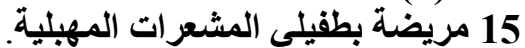

\begin{tabular}{|c|c|c|}
\hline \multicolumn{2}{|c|}{ المريضات } & \multirow{2}{*}{ الأعر اض السريرية } \\
\hline$\%$ & 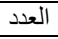 & \\
\hline 13.3 & 2 & سيلان فقط Discharge only \\
\hline 46.7 & 7 & سيلان مع حكة Discharge and itching \\
\hline 6.7 & 1 & $\begin{array}{c}\text { Discharge and سيلان مع احتباس بالبول } \\
\text { dysuria }\end{array}$ \\
\hline 13.3 & 2 & Itching only حكة فقط \\
\hline 20.0 & 3 & $\begin{array}{c}\text { Discharge , سيلان مع حكة واحتباس بالبول } \\
\text { itching and dysuria }\end{array}$ \\
\hline 100.0 & 15 & \\
\hline
\end{tabular}

\begin{tabular}{|c|c|c|}
\hline \multicolumn{2}{|c|}{ المريضنات } & \multirow{2}{*}{ طبيعة الأفرازات المهبلية } \\
\hline$\%$ & 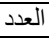 & \\
\hline 23.0 & 3 & سيلان عديم اللون Colorless discharge \\
\hline 15.0 & 2 & سيلان ذو رغوة Frothy discharge \\
\hline 31.0 & 4 & سيلان ابيض White to gray discharge \\
\hline 31.0 & 4 & $\begin{array}{c}\text { Yellow to green سيلان اصفر مخضر } \\
\text { discharge }\end{array}$ \\
\hline
\end{tabular}

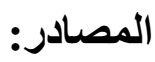

1. Hitchcock, P. J. 1999. Sexually transmitted diseases in Schaechter, M. , Engleberg, N. C. , Eisenstein, B. I. and Medoff, G. Mechanisms of Microbial Disease. $3^{\text {td }}$ ed Chanky, Inc. U. S.A. pp.611-620

2. Word Health Organization. 1995.An over view of selected curable sexually transmitted diseases, P.2-27.in, global program on AIDS. World Health Organinization, Geneva, Switzerland.

3. Cotech,M.F.,Pastorek.J.G.;Nugent, R.P.,Hiller,S.L.,Gibbs,R.S.,Martin,D. H.,Eschenba ch,D.A.;Edelman,R.;Carey,J.C.;Rega n,J.A.;Krohn,M.A.;Klebenoff,M.A.; Rao,A.V.and Rhoads,G.G. 1997. Trichomonas vaginalis associated with low birth weights, and preterm dilvery.Sex. Transm. Dis.,24:353360.

4. Goldstein, F., Goldman, M. B. and Cramer, D. W. 1993 . Relation of tubal infertility to a history of sexually transmitted diseases. Am J. Epidemiol., 137: 577-584.

5. Kharsany, A.B., Hoosen, A. A. Moodley, J. Bagaratee, J. and Gouws, E. 1993. The association 
urogenital trichomoniasis. J. Clin . Micobiol., 21:588-592.

22. Carney, J. A. , Unadkat, P. , Yule, A. , Rajakumar, R. ,Lacey,C.J. 1988 .New rapid latex-agglutination test for diagnosing Trichomonas vaginalis infection.,$J$. Clin.Pathol.,41:806-808.

23. Kurth, A., Whittington, L.H., Golden, M.R., Thomas-K.K., Holmes, K. K and Schwebke, J. 2004. Performance of anew, rapid assay for detection of Trichomonas vaginalis. J. Cline. Micobioliol., 42:2940-2943.

24. Kaydos-Danels, S.C., Miler, W.C., Hoffman, I., Banda, T., Dzinyemba, W., Martinson, F., Cohen, M.S. and Hobbs, M.M. .2003. Validation of a urine- based PCR- enzyme linked Immunosorbent assay for use in Clinical research settings to detect Trichomonas vaginalis in men. $J$. Clin. Micobioliol .,41: 318-323.

25. Wisdom, A. R.and Dunlop, E.M. 1965. Trichomoniasis: study of the disease and its treatment in women and men. Br. J.Vener.Dis., 41:90-96.

26. Wolner - Hanssen, P., Krieger, J. N., Steven,C. E., Kiviat, N.B., Koutsky, L., Critchlow, C., Derouen, T., Hillier, S. and Holmes, K. K. 1989. Clinical manifestations of vaginal trichomoniasis. JAMA., 261:571-576.

27. Perl, G. 1972. Errors in the diagnosis of Trichomonas vaginalis infection, as observed among 1199 patients . Am. Ass. of Obstet. Gynecol., 39:7-9

28. Reynolds, M. and Wilson, J. 1996. Is Trichomonas vaginalis still marker for other sexually transmitted infection in women? Int. J. STD. AIDS., 7:131-2.

29. Alderet, J.F.and Peterson, K.M. 1982. Host plasma proteins on surface of pathogenic Trichomonas vaginalis. Infec. Immunol., 37:755762. :areemerging pathogen. Clin. Obstet. Gynecol., 36:137-144.

14. Yereli, K., Balcioglu, I. C., Degerli, K., Ozbilgin, A. and Daldal, N. 1997. Incidence Trichomonas vaginalis among women having vaginal discharge in mansia, turkey . J. Egypt. Soc. Parasitol., 27:905-911.

15. Rodriguez-Martinez, H. A., Rosales, M., DeBello, L. G. and Ruiz -Moreno, A. .1973. Adequate staining of Trichomonas vaginalis by McManus periodic acid Schiff stain. J.Clin.Patlo., 59:741-746.

16. Borchardt, K. A., and Smith, R.F. 1991. An evaluation of an in Pouch TV culture method for diagnosing Trichomonas vaginalis infection. Genitourin. Med., 67:149

17. AL-Kaisi, A.A.R. 1994 . The incidence of Trichomonas vaginalis among females with vaginal discharge. M .Sc.Thesis.Coll.Med, Univ.Baghdad.

18. Borchardt, K. A., Zhang, M. Z. , Shing, H. and Flink, K . 1997. A comparison of the sensitivity of the In Pouch TV, Diamonds and Trichosel media for detection of Trichomonas vaginalis

Genitourin. Med ., 73:297-8

19. AL-Sheikh,S. A. A. .1995. Study of pathogencity and associated microorganisms of vaginal Trichomoniasis in Baghdad .M. Sc . thesis, Coll .Med.,AL-Nahrain Univ.

20. AL-Mudhaffar, Z.M.J. 1995. Trichomonas vaginalis infection: Clinical, immunological and biochemical studies among Iraq women complaining of vaginal discharge. M.Sc. thesis, Coll Med., AL-Nahrain Univ.

21. Cogne, M., Brasseur, P. and Ballet, J. J. 1985. Detection and characterization of serum antitrichomonal antibodies in 


$\begin{array}{lr}\text { immunoglobulin } & \text {-degrading } \\ \text { cysteine } & \text { proteinase } \\ \text { Trichomonas } & \text { vaginalis. }\end{array}$

Immunol., 63:3388-3395.
30. Alderete, J.F.and Garza, G.E. 1984 . Soluble Trichomonas vaginalis in cell-free culture supernatants. Mol. Biochem.parasitol.,13:147-158.

31. Prorenzano, D. and Alderete, J.F. 1995. Analysis of human

\title{
Evaluation the efficiency of Trichomonas vaginalis depending on clinical sings , direct examination ,culturing and serological test
}

\author{
Ekhlas mushref* \\ Ali H. Adhiah** \\ Amna Nsyif Jassim* \\ *Department of Biology, College of Women Science, University of Baghdad \\ ** Tropical- Biological Research Unit, College of Science, Univ. of Baghdad
}

\begin{abstract}
:
The adequacy of diagnostic tests, together with trichomoniasis associated clinical symptoms, were investigated in females suffering vaginitis, and they were referred to the Gynecology Department, Al-Yarmouk Teaching Hospital during the period December 2004 - June 2005. The total number of patients was 250 cases (age range: 18 - 52 years), and each patient was examined using a sterile speculum to obtain vaginal swabs for examination. The diagnosis with $T$. vaginalis was done in many methods. The direct methods included wet and stained (Leishman's stain) examinations and cultivation in different culture media (Kupferberg Trichomonas Broth Base; Trichomonas Agar Base; TAB and Trichomonas Modified CPLM), while the indirect methods were serological detections of anti-trichomonas antibodies in the sera of patients by using of indirect haemagglutination test (IHAT) and enzyme linked immunosorbent assay (ELISA). The results of this profile were as the following:

1. Out of 250 females with abnormal vaginal discharges, 15 patients (6\%) were infected with $T$. vaginalis.

2. The sensitivity of testing methods was different. It was 66.7 and $13.3 \%$ for wet and stained examinations, respectively. In culture examinations, the sensitivity was 60, 80 and $100 \%$ for Kupferberg, TAB and CPLM media, respectively, while the sensitivity IHAT and ELISA were 40 and $73.3 \%$, respectively.

3. The clinical sings of infection in women were discharge and itching (46.7\%), discharge with itching and dysuria (20.0\%), discharge only (13.3\%), itching only $(13.3 \%)$ and discharge with dysuria $(6.7 \%)$.

Therefore we can conclude that impossible to the clinical signs in diagnose of Trichomonasis because of the variation and the laboratory diagnosis is necessary especially the cultivation method.
\end{abstract}

